\title{
The Child-care Food and Activity Practices Questionnaire (CFAPQ): development and first validation steps
}

\author{
Jessica S Gubbels*, Ester FC Sleddens, Lieke CH Raaijmakers, Judith M Gies \\ and Stef PJ Kremers \\ NUTRIM School for Nutrition and Translational Research in Metabolism, Department of Health Promotion, Maastricht \\ University, PO Box 616, 6200 MD Maastricht, The Netherlands
}

Submitted 13 July 2015: Final revision received 24 September 2015: Accepted 9 November 2015: First published online 4 December 2015

\begin{abstract}
Objective: To develop and validate a questionnaire to measure food-related and activity-related practices of child-care staff, based on existing, validated parenting practices questionnaires.

Design: A selection of items from the Comprehensive Feeding Practices Questionnaire (CFPQ) and the Preschooler Physical Activity Parenting Practices (PPAPP) questionnaire was made to include items most suitable for the child-care setting. The converted questionnaire was pre-tested among child-care staff during cognitive interviews and pilot-tested among a larger sample of child-care staff. Factor analyses with Varimax rotation and internal consistencies were used to examine the scales. Spearman correlations, $t$ tests and ANOVA were used to examine associations between the scales and staff's background characteristics (e.g. years of experience, gender). Setting: Child-care centres in the Netherlands.

Subjects: The qualitative pre-test included ten child-care staff members. The quantitative pilot test included 178 child-care staff members.

Results: The new questionnaire, the Child-care Food and Activity Practices Questionnaire (CFAPQ), consists of sixty-three items (forty food-related and twenty-three activity-related items), divided over twelve scales (seven food-related and five activity-related scales). The CFAPQ scales are to a large extent similar to the original CFPQ and PPAPP scales. The CFAPQ scales show sufficient internal consistency with Cronbach's $\alpha$ ranging between 0.53 and 0.96 , and average corrected item-total correlations within acceptable ranges $(0 \cdot 30-0 \cdot 89)$. Several of the scales were significantly associated with child-care staff's background characteristics. Conclusions: Scale psychometrics of the CFAPQ indicate it is a valid questionnaire that assesses child-care staff's practices related to both food and activities.
\end{abstract}

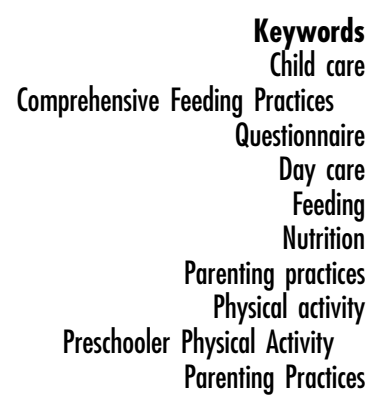

Energy balance-related habits (i.e. dietary intake, physical activity and sedentary behaviour) originate in early childhood and track into later life ${ }^{(1,2)}$. Parents can have a strong influence on these habits by the parenting practices they use $^{(3)}$. Parenting practices are content-specific acts of parenting ${ }^{(4)}$, and include setting rules about dietary intake or activity behaviour, acting as a role model, and educating children about food and physical activity ${ }^{(5-8)}$.

Various reviews have summarized the many studies regarding the influence of parenting practices on children's dietary intake (e.g. references 9 and 10) and physical activity and sedentary behaviour (e.g. reference 11). With regard to food-related parenting practices ${ }^{(9)}$, instrumental and emotional feeding, in which food is used to change children's behaviour or mood, seem less effective or sometimes show undesirable effects. Stimulating healthy intake seems to be a more promising approach. Also with regard to physical activity ${ }^{(11)}$, supportive and encouraging parenting practices seem to hold the most promising results. In line with the growing number of studies examining energy balance-related parenting, there are also numerous instruments to assess food-related ${ }^{(12)}$ and activity-related $^{(11,13,14)}$ parenting, including various validated instruments.

However, an increasing number of children are attending non-parental child care for one or more days per week; more than half of European toddlers attend child-care or pre-school education facilities ${ }^{(15)}$. In view of the increasing child-care use, various authors have called for increased attention to the influence of child-care staff practices on children's energy balance-related behaviour ${ }^{(16-19)}$. Child-care use is associated with an increased overweight 
risk throughout childhood ${ }^{(20,21)}$. Moreover, differences between children's dietary intake, physical activity and sedentary behaviour can be partially attributed to the childcare centre or the pre-school the child is attending ${ }^{(22,23)}$. However, a limited number of studies have examined the association between child-care practices and children's nutrition. For instance, we recently showed ${ }^{(24)}$ that children ate more vegetables when child-care staff encouraged them. Children ate more fruit and less sweet snacks when staff involved them in food preparation ${ }^{(24)}$. Other studies have shown beneficial effects of staff modelling healthy food intake or talking about healthy food ${ }^{(25)}$, or combining these practices by using enthusiastic modelling, in which staff verbally confirmed that the food they tasted, tasted $\operatorname{good}^{(26)}$. As regards physical activity, encouragement of physical activity by staff has been linked to increased activity levels ${ }^{(19,27)}$. Findings with regard to child-care staff's initiation of and participation in play are mixed ${ }^{(27,28)}$.

A recent review of physical activity and healthy eating environmental audit tools in youth care settings indicated that there are a handful of audit tools for the child-care setting ${ }^{(29)}$. However, most of these instruments focus mainly on the physical child-care environment or child-care policies. Staff's food-related and activity-related practices are included in some instruments, although this concerns only a limited selection of practices (e.g. references 30 and 31). Hughes et al. have developed a questionnaire to assess child-care staff's feeding styles, which are conceptually different from specific food-related practices $^{(32)}$. In addition, Dev and colleagues have used parenting practices instruments to assess child-care staff's food-related practices ${ }^{(33,34)}$, although these were not validated for the child-care setting. To our knowledge, validated questionnaires to specifically assess the broad range of child-care staff's food-related and activity-related practices in detail are not yet available.

The lack of such questionnaires to specifically assess child-care staff practices is a large contrast to the abundance of questionnaires to assess parenting practices and reflects the gap between our knowledge regarding practices in both settings (home and child care) ${ }^{(24)}$. Therefore, the aim of the current study was to develop and validate a questionnaire to measure food-related and activity-related practices of child-care staff, based on existing, validated parenting practices questionnaires.

\section{Methods}

\section{Questionnaire selection}

Two parenting practices questionnaires were selected for conversion to the child-care setting: the Comprehensive Feeding Practices Questionnaire (CFPQ) of MusherEizenman and Holub ${ }^{(35)}$ assessing food-related parenting practices; and the Preschooler Physical Activity Parenting Practices (PPAPP) questionnaire of O'Connor et al. ${ }^{(36)}$ assessing activity-related practices. The selection was done by three of the authors of the current paper (J.S.G., E.F.C.S. and S.P.J.K.), who are experts in the field of parenting and/or child care. The questionnaires were selected based on previous studies using parenting practices instruments in the child-care setting ${ }^{(33,34)}$, the findings of recent reviews of parenting practices instruments ${ }^{(11-14)}$ and an additional literature review to find any questionnaires published after these reviews. Criteria for the selection of the questionnaires were the validity and suitability of the questionnaire for the age group ( $0-4$ years old) and the suitability of the item content for translation to the child-care setting. All decisions were made through extensive author review meetings.

The CFPQ has been previously used to assess child-care staff's food-related practices in the child-care setting by Dev and colleagues ${ }^{(33,34)}$. However, they applied the original scales of the parenting version ${ }^{(35)}$ to their childcare version ${ }^{(33,34)}$. Building on the work of Dev et al. and the considerations above, we decided to select the CFPQ for the current validation study. The CFPQ is partly based on one of the most widely used scales in the child feeding literature: the Child Feeding Questionnaire (CFQ), developed by Birch et al. ${ }^{(37)}$. However, because the CFQ did not fully capture the range of food-related practices, the CFPQ was developed ${ }^{(35)}$. The CFPQ assesses food parenting practices using forty-nine items divided over twelve scales (see online supplementary material, Supplemental Table 1): Child control, Emotion regulation, Encourage balance and variety, Environment, Food as reward, Involvement, Modelling, Monitoring, Pressure to eat, Restriction for health, Restriction for weight control and Teaching about nutrition. All items are answered using a 5-point Likert scale ranging from 'never' to 'always' for the questions and from 'disagree' to 'agree' for the statements. The validation studies of the CFPQ show good fit of the final model, with Cronbach's $\alpha$ ranging from 0.58 to $0 \cdot 81^{(35)}$. The items of the CFPQ were independently translated to Dutch by four of the authors (J.S.G., E.F.C.S., L.C.H.R. and J.M.G.). In the case of disagreement, the fifth author (S.P.J.K.) was involved to decide on the final item.

The PPAPP measures activity-related parenting practices using thirty-two items on two main scales: Encouraging physical activity (seventeen items) and Discouraging physical activity (fifteen items) ${ }^{(36)}$ (see online supplementary material, Supplemental Table 2). The Encouraging and Discouraging scales are split up further in various subscales and single items. The Encouraging scale includes the Engagement subscale and two single items. The Discouraging scale consists of four subscales: Promote inactive transport, Promote screen time, Psychological control and Restriction for safety concern. Answers are on a 5-point Likert scale ranging from 'never' to 'always'. Validation studies of the questionnaire showed a test-retest reliability ranging from 0.56 to 0.85 , and Cronbach's $\alpha$ values between 0.50 and $0.90^{(36,38)}$. A Dutch 
translation of the PPAPP was already available from a previous study ${ }^{(39)}$. The translation procedure for the PPAPP was in line with that of the CFPQ, with multiple experts independently translating the questionnaire.

\section{Questionnaire conversion}

After the CFPQ and PPAPP were selected, their items were reviewed by the present authors for applicability in the child-care setting. Several items were dropped because they were not applicable for the child-care setting. For the CFPQ, four items were dropped (see online supplementary material, Supplemental Table 1), leaving forty-five items. For instance, 'I encourage my child to participate in grocery shopping' from the Involvement scale was dropped, as children do not participate in grocery shopping in child-care. For the PPAPP, five items were dropped (see Supplemental Table 2), leaving twentyseven items. An example of an item from the PPAPP that was not applicable was 'How often do you take your child to sport practice or game in which he/she is enrolled?'

The remaining items were translated to the child-care setting. In line with the translation to Dutch, the items were independently translated to the child-care setting by four of the authors (J.S.G., E.F.C.S., L.C.H.R. and J.M.G.). In the case of disagreement, the fifth author (S.P.J.K.) was involved to decide on the final item. For most items, the conversion to the child-care setting simply meant replacing 'my child' by 'the children'. For instance, 'I show my child how much I enjoy eating healthy foods' was converted to 'I show the children how much I enjoy eating healthy foods'. For other items, additional changes had to be made. For instance, 'How often do you play a sport or active game together as a family?' was changed to 'How often do you play a sport or active game together with the children (and perhaps with other child-care staff)?'

\section{Qualitative pre-test}

To pre-test the developed questionnaires, child-care staff were approached to participate in a cognitive interview. The aim of this cognitive interview was to find errors in the questionnaire or unsuitable items, including unclear instructions or answer options, that could influence the outcome of the questions ${ }^{(40)}$. For the interviews, thirteen child-care centres in the Netherlands were contacted via telephone. Four child-care centres agreed to participate and a total of ten child-care staff members from these four centres were interviewed. The participants were all female and their age ranged between 20 and 55 years.

First, the researchers explained the procedure to the participants. During the interviews, participants were asked to indicate good questions with ' + ', questions that can be improved with '-', and with ' 0 ' when they did not have an opinion. When participants indicated a question with '+', it was discussed what was good about the question. When participants rated a question with '-', it was discussed what could be improved about the question. Next, there were some general questions about the clarity of the instructions and the answer options of the items. Subsequently, the applicability of some specific items was discussed.

The interviews were recorded on a voice-recording device. Additionally, the interviewers took field notes. Based on the outcomes of the interviews, a few additional changes had to be made to the items. These were mostly minor changes in wording or sentence structure. In some cases, examples were added to the items for clarification. Furthermore, several additional items were dropped based on the responses of the interview participants. These were five items of the CFPQ and four items of the PPAPP (see online supplementary material, Supplemental Tables 1 and 2). For the CFPQ, five items of the Restriction for weight control scale were deleted, as the child-care staff could not relate to these questions; weight control was beyond their influence and beyond their responsibility. Another example was that all child-care staff indicated that they had an enclosed and locked playground. The PPAPP questions regarding not letting children play outside because of worries about traffic, crime or strangers thus were not relevant. Supplemental Tables 1 and 2 show which items were deleted at this stage.

The combined and converted pilot-test version of the questionnaire, named the Child-care Food and Activity Practices Questionnaire (CFAPQ), contained sixty-three items: forty regarding diet and twenty-three regarding physical activity. The items included in the CFAPQ are shown in online supplementary material, Supplemental Tables 1 and 2.

\section{Procedure of pilot test}

The pilot-test version of the questionnaire was pilot-tested among a larger sample of child-care staff. In addition to the CFAPQ items, several items were added regarding participants' demographics. These were the child-care staff's age (18-25 years, 26-35 years, 36-45 years, 46-55 years, 56-65 years, $>65$ years), gender, weight (in kilograms), height (in centimetres), educational level (child-care staff education (in Dutch: Sociaal Pedagogisch Werker) level 3, 4 or 5), whether they had children themselves, total number of groups in the child-care centre in which they were working at the time of the questionnaire, number of years working in the child-care centre in which they were working at the time of the questionnaire, and total number of years working in the child-care setting in general.

A total of 1028 randomly selected child-care centres were approached, mostly via email or telephone. Email addresses and telephone numbers were obtained from a Dutch national database of child-care centres and preschools (in Dutch: Landelijk Register Kinderopvang en Peuterspeelzalen ${ }^{(41)}$ ). Child-care centres had the ability to complete the questionnaire online ${ }^{(42)}$ or to request a paper version, which was sent to them with a prepaid return envelope. Participants were recruited during April 2014. Data collection took place during April and May 
2014. In total, 256 child-care staff members agreed to participate. It is unknown whether more than one staff member participated per child-care centre. Of the 256 participants, 178 (69.5\%) completed at least part of the questionnaire and were retained for further analyses.

\section{Statistical analyses}

Statistical analyses were performed using the statistical software package IBM SPSS Statistics 21. Descriptive statistics were used to describe the background characteristics of the sample. Both internal reliability coefficients (Cronbach's $\alpha$ ) and corrected item-total correlations (CITC) were calculated. A cut-off point of 0.50 for Cronbach's $\alpha$ was used ${ }^{(43)}$. CITC values above 0.30 were regarded as 'good' and values below 0.15 as 'unreliable ${ }^{(44)}$.

To check whether the data were adequate for factor analysis, the Kaiser-Meyer-Olkin measure of sampling adequacy and Bartlett's test of sphericity were measured. A Kaiser-Meyer-Olkin value of 0.5 was considered suitable. Furthermore, the Bartlett's test of sphericity needed to be significant ${ }^{(44)}$. A principal components analysis with Varimax rotation was performed on items of the CFAPQ (the forty items of the food-related practices and twentythree of the activity-related practices part separately) to determine whether the original factor structure would be replicated in this sample. All factors had to have an eigenvalue above 1·0. The scree plot was used to determine the number of factors ${ }^{(45,46)}$. The cut-off point for factor loadings was $0 \cdot 30^{(45)}$. In case the factor structure did not equal the factor structures of the original questionnaires, we forced to retrieve fewer factors to potentially improve the interpretability of the results.

In addition, the correlations between the scales based on the factor solutions were examined using Pearson correlations. Correlations between the scales and childcare staff's background characteristics were examined using independent-samples $t$ tests for bivariate variables (i.e. gender, whether they had own children and educational level), ANOVA for categorical variables (i.e. age, years of experience in current centre and in general) and Spearman correlations for continuous variables (i.e. BMI and number of groups in current centre).

\section{Results}

\section{Background characteristics of the participants of the pilot test}

A total of 178 child-care staff members filled out the questionnaire. Table 1 shows their background characteristics. The vast majority of the participants were female (98.9\%). The largest age group was 26-35 years $(42.7 \%)$. Most had a normal weight $(70.4 \%)$ and did have children themselves (65.2\%). Most participants worked in a mixed age group (53.7\%) and had been working at their current child-care centre for less than 5 years $(44.4 \%)$.

\section{Factor analyses and psychometric evaluation of the CFAPQ}

The online supplementary material, Supplemental Tables 3 and 4 show the frequencies and means of the answers to the singe items. The data were considered appropriate for factor analysis, since the Kaiser-Meyer-Olkin measure of sampling adequacy was 0.66 for the food-related practices items and 0.78 for the activity-related practices items. The Bartlett's test of sphericity was significant for both parts of the questionnaire at a level of $<0 \cdot 001$.

\section{Food-related practices}

The factor analysis was based on forty items. As we repeatedly found that one item belonging to the scale of Encouraging balance and variety ('Do you encourage the children to eat healthy foods before unhealthy ones?') did not load on the intended factor, we decided to delete this item from the factor analysis. However, we decided to retain this item for further analyses as a single item. Factor analysis on the remaining thirty-nine items resulted in a

Table 1 Background characteristics of participants in the pilot test: child-care staff members ( $n$ 178), the Netherlands, April-May 2014

\begin{tabular}{|c|c|c|c|c|}
\hline & $n$ & $\%$ & Mean & SD \\
\hline \multicolumn{5}{|l|}{ Gender } \\
\hline Female & 176 & 98.9 & & \\
\hline Male & 2 & $1 \cdot 1$ & & \\
\hline \multicolumn{5}{|l|}{ Age group } \\
\hline $18-25$ years & 15 & 8.4 & & \\
\hline $26-35$ years & 76 & $42 \cdot 7$ & & \\
\hline $36-45$ years & 36 & $20 \cdot 2$ & & \\
\hline $46-55$ years & 35 & 19.7 & & \\
\hline $56-65$ years & 16 & 9.0 & & \\
\hline BMI $\left(\mathrm{kg} / \mathrm{m}^{2}\right)$ & & & 23.9 & $2 \cdot 2$ \\
\hline Normal weight (20-25) & 114 & $70 \cdot 4$ & & \\
\hline Overweight (25-30) & 38 & 23.5 & & \\
\hline Obese $(>30)$ & 10 & 6.2 & & \\
\hline \multicolumn{5}{|l|}{ Educationt } \\
\hline Child-care staff level 3 & 39 & $22 \cdot 4$ & & \\
\hline Child-care staff level 4 & 63 & $36 \cdot 4$ & & \\
\hline Child-care staff level 5 & 88 & $50 \cdot 9$ & & \\
\hline \multicolumn{5}{|l|}{ Number of own children } \\
\hline None & 62 & $34 \cdot 8$ & & \\
\hline One or more & 116 & 65.2 & & \\
\hline \multicolumn{5}{|l|}{ Type of groupt } \\
\hline Baby group (0-1 years) & 24 & $13 \cdot 6$ & & \\
\hline Toddler group ( $2-4$ years) & 43 & $24 \cdot 3$ & & \\
\hline Mixed age group ( $0-4$ years) & 95 & 53.7 & & \\
\hline Other type of group & 39 & $22 \cdot 0$ & & \\
\hline \multicolumn{5}{|l|}{ Total experience in child-care } \\
\hline$<5$ years & 37 & $20 \cdot 8$ & & \\
\hline $6-10$ years & 51 & 28.7 & & \\
\hline $11-15$ years & 40 & 22.5 & & \\
\hline$>15$ years & 50 & $28 \cdot 1$ & & \\
\hline \multicolumn{5}{|l|}{ Experience in the current centre } \\
\hline$<5$ years & 79 & 44.4 & & \\
\hline $6-10$ years & 43 & 24.2 & & \\
\hline $11-15$ years & 27 & $15 \cdot 2$ & & \\
\hline$>15$ years & 29 & $16 \cdot 3$ & & \\
\hline Total number of groups at current centre & & & 3.6 & $2 \cdot 2$ \\
\hline
\end{tabular}

$n$ deviates from total sample size due to missing values. Percentages presented in the table represent valid percentages. †Multiple answers possible. 
Table 2 Factor structure of the Restriction scale of the food-related practices items of the Child-care Food and Activity Parenting Questionnaire (CFAPQ), percentage of variance accounted for by each factor and reliability estimates

\begin{tabular}{|c|c|c|c|}
\hline Food-related practices items: Restriction & Factor 1 & Factor 2 & $\begin{array}{l}\text { Forced to } \\
\text { one factor }\end{array}$ \\
\hline If I did not guide or regulate the children's eating, they would eat too many junk foods & & 0.71 & 0.58 \\
\hline I have to be sure that the children do not eat too much of their favourite products & 0.38 & 0.52 & 0.71 \\
\hline $\begin{array}{l}\text { I have to be sure that the children do not eat too many sweets (for example, candy, ice cream, } \\
\text { cookies or pastries) }\end{array}$ & 0.72 & & 0.65 \\
\hline $\begin{array}{l}\text { I have to be sure that the children do not eat too many high-fat foods (for example, cheese, } \\
\text { sausage, cookies) }\end{array}$ & 0.75 & & 0.47 \\
\hline $\begin{array}{l}\text { If a child eats more than usual at a one meal, I try to restrict his/her eating at the next meal } \\
\text { If I did not guide or regulate the children's eating, they would eat too much of their favourite foods }\end{array}$ & 0.63 & 0.78 & $\begin{array}{l}0.43 \\
0.62\end{array}$ \\
\hline $\begin{array}{l}\text { Percentage of variance accounted for } \\
\text { Cronbach's a coefficient } \\
\text { Average corrected item-total correlation } \\
\text { Range corrected item-total correlation } \\
\text { Mean } \\
\text { SD }\end{array}$ & 34.01 & $19 \cdot 25$ & $\begin{array}{c}34.01 \\
0.60 \\
0.34 \\
0.23-0.44 \\
3.37 \\
0.63\end{array}$ \\
\hline
\end{tabular}

$n$ 159. Only factor loadings higher than the absolute value of 0.30 are reported. Bold values represent the final factor structure.

twelve-factor solution. The six items of the scale of Restriction had multiple cross-loadings on several factors, even after forcing the factor solution to retrieve fewer factors. We therefore deleted the full scale of restriction and performed a separate factor analysis on the six items conceptually belonging to Restriction. Even though a two-factor solution was found, we forced to a one-factor solution and the findings were acceptable (see Table 2). The factor loadings ranged from 0.43 to 0.71 , and internal consistency was adequate (Cronbach's $\alpha=0.60$ and the CITC ranged from 0.23 to 0.44 for the six items).

Factor analysis on the remaining thirty-three items retrieved a nine-factor solution with eigenvalues higher than 1 , accounting for $64.68 \%$ of the total variance. All except one (the scale of Food as a reward) of the original scales of the $\mathrm{CFPQ}^{(35)}$ did load on the intended factors. When looking at the rotated factor solution, the three items conceptually belonging to the scale of Food as a reward had high factor loadings on multiple factors. We therefore forced the factor analyses to retrieve an eight-factor solution, accounting for $61 \cdot 12 \%$ of the total variance. In line with the nine-factor solution, cross-loadings $(>0 \cdot 30)$ were found for the items of the scale Food as a reward on multiple factors. Finally, we forced to a seven-factor solution. This factor solution accounted for $57.35 \%$ of the total variance with eigenvalues higher than 1 . The findings of this factor solution are presented in Table 3. Most of the scale items loaded as expected, conforming to the study of Musher-Eizenman and Holub $^{(35)}$. Three factors retrieved contained two scales: factor 2 was represented by the scale of Encourage balance and variety and the scale of Modelling; factor 3 was represented by the scales of Environment and Involvement; and factor 7 was represented by the scales of Emotion regulation and Food as a reward. The other factors contained a single scale of the original constructed scale: Monitoring, Teaching about nutrition, Pressure to eat and Child control. Most items loaded onto a single factor. A few had loadings higher than the absolute value of 0.30 on two and sometimes three factors. These items were allocated to the factor where the theoretical fit was best, conforming to the original factor structure. For two items, one of the scale of Encourage balance and variety and one of the scale of Child control, the factor loading was below $0 \cdot 30$. These items were retained in the final factor solution to provide better comparability with the original factor structure of the CFPQ.

The internal consistency coefficients for the scales are displayed in Table 3 and can be considered adequate, ranging from 0.53 to 0.96 . The average CITC are also within acceptable ranges $(0 \cdot 30-0 \cdot 89)$. In addition, Tables 2 and 3 show the means and standard deviations of the food-related CFAPQ scales.

\section{Activity-related practices}

The factor analysis was based on twenty-two items, instead of twenty-three items. We excluded the item 'How often do you have outdoor toys available for the children (for example, skipping ropes, balls, etc.)?', as this was the only item representing availability of physical activity materials and therefore did not represent a certain type of practice or behaviour a child-care staff member can perform. The factor analysis revealed a seven-factor solution with eigenvalues higher than 1 , accounting for $68.25 \%$ of the total variance. When looking at the rotated factor solution, the three items on the Promote screen time scale (Discouragement) clustered together with factor loadings ranging from 0.54 to 0.86 . However, the five items on the Psychological control scale (Discouragement) had high loadings on two factors. In addition, items on the scale of Encouragement had high loading on four factors. Three factors represented the following constructs conceptually belonging to Encouragement of physical activity, namely Modelling (factor 1), Teaching/autonomy support (factor 2) and Going outdoors (factor 5). The item 'How often do you dance with the children?' was the only item 
Table 3 Factor structure of the food-related practices items of the Child-care Food and Activity Parenting Questionnaire (CFAPQ), percentage of variance accounted for by each factor and reliability estimates

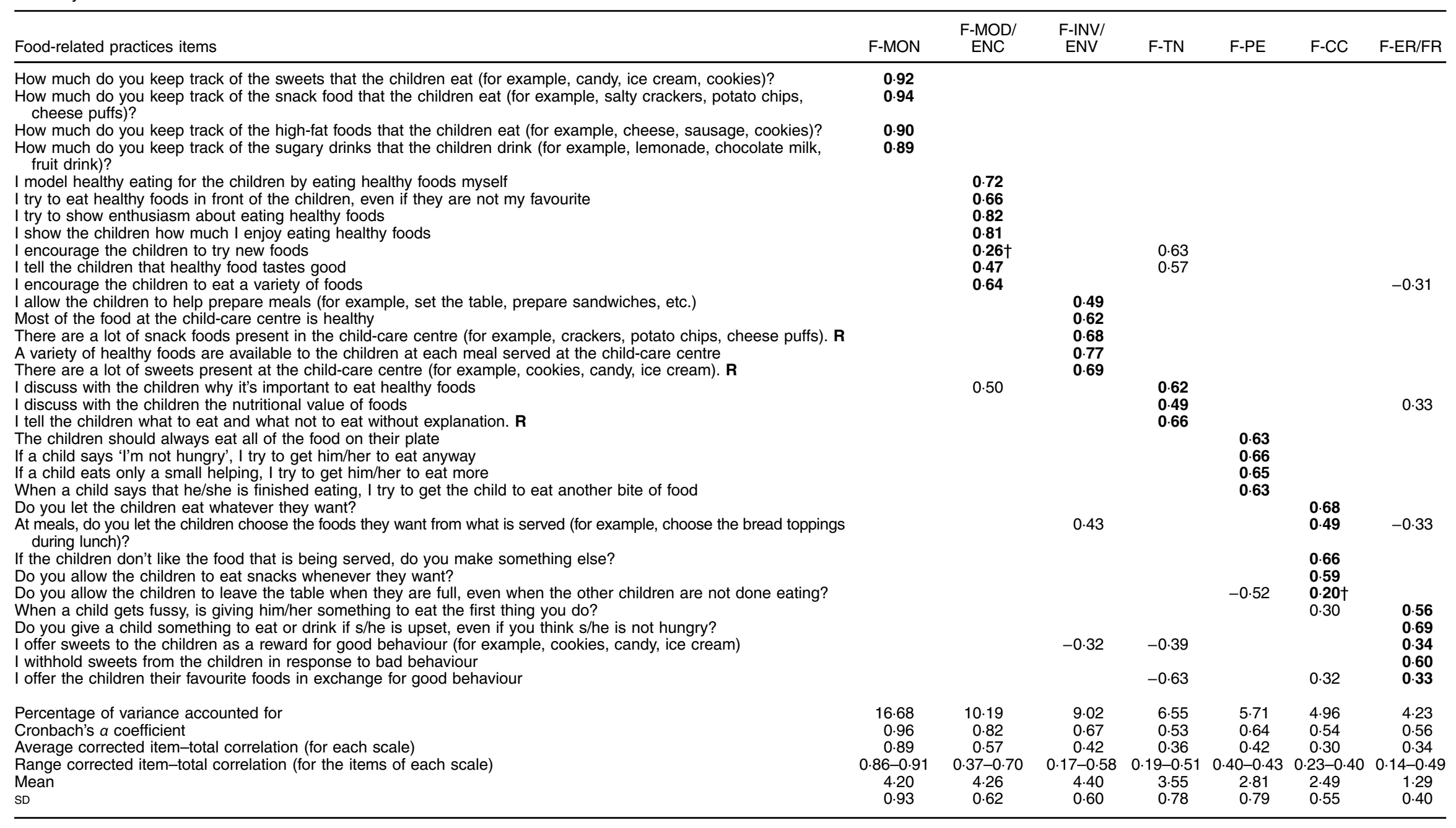

$n$ 111. Factors are labelled as follows: F-MON, food-related Monitoring; F-MOD/ENC, food-related Modelling/Encourage balance and variety; F-INV/ENV, food-related Involvement/Environment; F-TN, food-related Teaching about nutrition; F-PE, food-related Pressure to eat; F-CC, food-related Child control; F-ER/FR, food-related Emotion regulation/Food as reward. Only factor loadings higher than the absolute value of 0.30 are reported. Sample size used to measure internal consistency estimates: F-MON, $n 125$; F-MOD/ENC, $n$ 158; F-INV/ENV, $n$ 159; F-TN, $n$ 158; F-PE, $n$ 159; F-CC, $n$ 140; F-ER/FR, $n$ 155. The following item was not included in the factor analyses, but retained as a single item: 'Do you encourage the children to eat healthy foods before unhealthy ones?' (mean $=4 \cdot 28, S D=1 \cdot 19)$. $R=$ reverse coded. Bold values represent the final factor structure. †Although the factor loading was below 0.30 , it is depicted in the table and on theoretical grounds the item has provisionally been retained on this factor 
loading on the fourth factor of Encouragement, factor 7 (factor loading of $0 \cdot 70$ ), although this item also loaded on factor 1 (Encouragement, Modelling) with a factor loading of $0 \cdot 28$. As this item conceptually belongs to 'Modelling', we forced the factor analyses to a six-factor solution.

The six-factor solution accounted for $63.52 \%$ of the total variance with eigenvalues higher than 1 . In agreement with the seven-factor solution, the five items on the Psychological control scale (Discouragement) still had high loadings on two factors. However, the item 'How often do you dance with the children?' now loaded onto the first (Modelling) and second factor (Teaching/ autonomy support) belonging to Encouragement, with a factor loading of 0.32 and 0.33 , respectively. We did again force the factor analyses, but now to a five-factor solution.

The five-factor solution explained $58.29 \%$ of the variance in responses of the physical activity practices part of the CFAPQ, with eigenvalues higher than 1 . The findings of this factor solution are presented in Table 4. With regard to the Discouragement scale, we perfectly found the two scales of Psychological control (factor 2) and Promote screen time (factor 3). All items of the two scales had the highest factor loading on the factor the item belongs to. With regard to the Encouragement scale, three sub-scales were created, one containing eight items representing Modelling of physical activity (factor 1), another containing five items representing Teaching/ autonomy support of physical activity (factor 4), and the final factor containing two items representing Going outdoors (factor 5). Some items of factor 4 had higher factor loadings on factor 1 , but were retained to factor 4 as the theoretical fit was best on this factor (i.e. the items 'How often do you say positive things to motivate children to be more active?' and 'How often do you teach the children new and different ways to be active?').

The psychometric evaluation of the created five scales is presented in Table 4. Cronbach's $\alpha$ coefficients for the five scales ranged from 0.58 to $0 \cdot 85$. Table 4 also presents average CITC, which suggest adequate consistency of item content within the scales $(0 \cdot 35-0 \cdot 62)$. In addition, Table 4 shows the means and standard deviations of the activity-related CFAPQ scales.

\section{Associations between the CFAPQ scales}

Table 5 shows the correlations between the CFAPQ scales. Generally, 'desirable' practices were positively correlated with other desirable practices (e.g. food-related Modelling and Encouragement of balance and variety (F-MOD/ENC) showed a strong positive correlation with food-related Teaching about nutrition (F-TN), $r=0.53, P<0.001$ ) and 'undesirable' practices were positively correlated with other undesirable practices (e.g. activity-related Psychological control (A-PC) was positively correlated with Promoting screen time (A-PST), $r=0 \cdot 24, P<0 \cdot 01$ ). In addition, there were various significant correlations between food-related and activity-related practices, most often when they concerned similar practices although regarding a different behaviour. For instance, food-related Modelling and Encouragement (F-MOD/ENC) was positively associated with activity-related Modelling (A-MOD); $r=0.33$, $P<0.01)$ and food-related Teaching about nutrition (F-TN) was positively associated with activity-related Teaching and Autonomy support (A-T/AS; $r=0 \cdot 36, P<0 \cdot 001$ ).

\section{Associations between the CFAPQ and background characteristics}

The online supplementary material, Supplemental Table 5 shows the final CFAPQ. With regard to correlations between the CFAPQ and child-care staff's background characteristics, younger child-care staff scored higher on the activity-related scale Going outdoors (A-GO) than older staff (18-25 years, 3.28; 26-35 years, 2.94; 36-45 years, 2.91; 46-55 years, 3.02; 56-65 years, 2.25; $P=0.008$ ). Compared with child-care staff who did not have children themselves, child-care staff who did have children scored lower on the food-related scale Emotion regulation/Food as reward (F-ER/FR; 1.39 v. 1.23 respectively, $P=0.016)$, and the activity-related scales Psychological control (A-PC; 1.85 v. 1.67, $P=0.015)$ and Going outdoors (A-GO; 3.11 v. 2·80, $P=0 \cdot 015$ ). Child-care staff's BMI was positively correlated with the item 'How often do you have outdoor toys available for the children?' ( $r=0 \cdot 198, P=0 \cdot 015)$. Participants' educational level was not significantly related to any of the CFAPQ scales or single items. The association between participant's gender and the CFAPQ scales could not be examined due to the limited number of male child-care staff members in the study.

Child-care staff working in a toddler group (2-4 years) scored higher on the activity-related Teaching/Autonomy support (A-T/AS) scale, compared with child-care staff in other age groups $(3.73 v .3 .51, P=0.016)$. With regard to the scores on the food-related Modelling/Encourage balance and variety (F-MOD/ENC) scale in relation to participants' experience in the current child-care centre, an inverted U-shaped association was found: participants who had been working at the same child-care centre for 11-15 years scored the highest on this scale. Participants with less or more experience scored lower $(\leq 5$ years, $3 \cdot 61$; 6-10 years, 3.64; 11-15 years, 3.76; >15 years, 3.71; $P=0.006$ ). A similar reversed U-shaped association was found between the Modelling/Encourage balance and variety (F-MOD/ENC) scale and total number of years working in child-care, although the scores were especially low in the participants with less than 5 years of experience in child care ( $\leq 5$ years, $3 \cdot 46$; $6-10$ years, $3 \cdot 70 ; 11-15$ years, $3.74 ;>15$ years, $3.66 ; P=0 \cdot 049)$. There was a negative correlation between the total number of groups in the child-care centre and the activity-related scale Going outdoors (A-GO; $r=-0 \cdot 17, P=0 \cdot 036$ ), indicating that staff working in larger child-care centres less often took the children on field trips. 
Table 4 Factor structure of the activity-related practices items of the Child-care Food and Activity Parenting Questionnaire (CFAPQ), percentage of variance accounted for by each factor and reliability estimates

\begin{tabular}{|c|c|c|c|c|c|}
\hline $\begin{array}{l}\text { Activity-related practices items } \\
\text { How often do you... }\end{array}$ & A-MOD† & $A-P C$ & A-PST & A-T/AS† & A-GO† \\
\hline 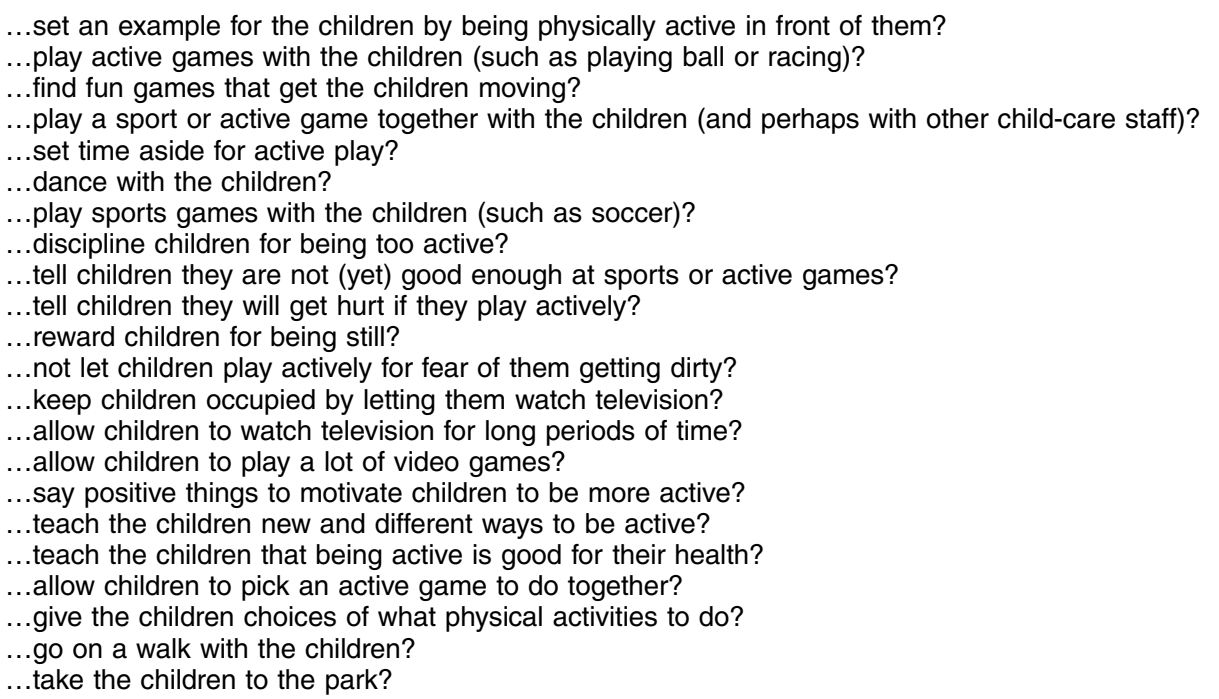 & $\begin{array}{l}0.74 \\
0.71 \\
0.76 \\
0.82 \\
0.62 \\
0.47 \\
0.77\end{array}$ & $\begin{array}{l}0.66 \\
0.58 \\
0.70 \\
0.53 \\
0.56\end{array}$ & $\begin{array}{l}0.83 \\
0.85 \\
0.53\end{array}$ & $\begin{array}{l}0.47 \\
0.21 \\
0.48 \\
0.60 \\
0.59 \\
0.66\end{array}$ & $\begin{array}{l} \\
0.87 \\
0.81\end{array}$ \\
\hline $\begin{array}{l}\text { Percentage of variance accounted for } \\
\text { Cronbach's } a \text { coefficient } \\
\text { Average corrected item-total correlation (for each scale) } \\
\text { Range corrected item-total correlation (for the items of each scale) } \\
\text { Mean } \\
\text { SD }\end{array}$ & $\begin{array}{r}26.58 \\
0.85 \\
0.62 \\
0.43-0.75 \\
3.66 \\
0.48\end{array}$ & $\begin{array}{r}10.86 \\
0.58 \\
0.35 \\
0.24-0.54 \\
1.74 \\
0.48\end{array}$ & $\begin{array}{r}8.10 \\
0.68 \\
0.51 \\
0.40-0.59 \\
1.28 \\
0.38\end{array}$ & $\begin{array}{r}7.21 \\
0.75 \\
0.53 \\
0.47-0.59 \\
3.57 \\
0.51\end{array}$ & $\begin{array}{r}5.55 \\
0.76 \\
0.61 \\
0.61-0.61 \\
2.92 \\
0.79\end{array}$ \\
\hline
\end{tabular}

$n$ 116. Factors are labelled as follows: A-MOD, activity-related Modelling; A-PC, activity-related Psychological control; A-PST, activity-related Promote screen time; A-T/AS, activity-related Teaching/Autonomy support; A-GO, Activity-related Going outdoors. Only factor loadings higher than the absolute value of 0.30 are reported. Bold values represent the final factor structure.

TThe original 'encouragement factor of the Preschooler Physical Aclivily Parenting Practices (PPAPP) questionnaire was not confirmed, but was divided into three diferent subscales, namely A-MOD, A-T/AS and A-GO. Sample size used to measure internal consistency estimates: A-MOD, $n$ 158; A-PC, $n$ 156; A-PST, $n$ 124; A-T/AS, $n$ 154; A-GO, $n$ 158. The single item 'How often do you have outdoor toys available for the children (e.g. skipping ropes, balls)?' was not included in the factor analysis, but retained as a single item (mean $=4 \cdot 66, \mathrm{SD}=0.51$ ). 
Table 5 Correlations between the child-care practices as measured by the Child-care Food and Activity Parenting Questionnaire (CFAPQ)

\begin{tabular}{|c|c|c|c|c|c|c|c|c|c|c|c|c|}
\hline & F-MON & F-MOD/ENC & F-INV/ENV & F-TN & F-PE & $\mathrm{F}-\mathrm{CC}$ & F-ER/FR & A-MOD & $A-P C$ & A-PST & A-T/AS & A-GO \\
\hline $\begin{array}{l}\text { F-R } \\
\text { F-MON } \\
\text { F-MOD/ENC } \\
\text { F-INV/ENV } \\
\text { F-TN } \\
\text { F-PE } \\
\text { F-CC } \\
\text { F-ER/FR } \\
\text { A-MOD } \\
\text { A-PC } \\
\text { A-PST } \\
\text { A-T/AS }\end{array}$ & $0.24^{\star \star}$ & $\begin{array}{l}0.34^{\star \star \star} \\
0.24^{\star \star}\end{array}$ & 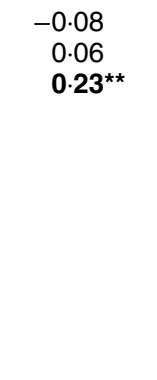 & 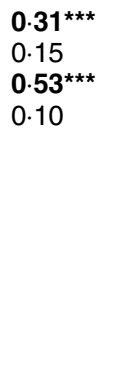 & $\begin{array}{c}0.10 \\
-\mathbf{0 . 1 9} \\
0.03 \\
-0.09 \\
0.03\end{array}$ & 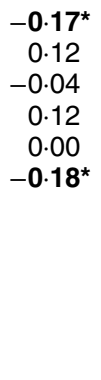 & $\begin{array}{c}0.05 \\
-0.10 \\
-0.09 \\
-\mathbf{0 . 1 9} \\
-0.07 \\
\mathbf{0 . 1 8 ^ { \star }} \\
-0.04\end{array}$ & $\begin{array}{l}0.12 \\
0.12 \\
\mathbf{0 . 3 3} \\
0.06 \\
\mathbf{0}^{\star \star 2} \mathbf{8}^{\star \star \star} \\
0.00 \\
0.08 \\
-0.13\end{array}$ & $\begin{array}{l}0.12 \\
-0.12 \\
-0.06 \\
-0.21^{\star \star} \\
-0.01 \\
0.40^{\star \star \star} \\
0.04 \\
\mathbf{0 . 3 4} \\
-0.02\end{array}$ & $\begin{array}{c}-0.02 \\
-0.16 \\
-\mathbf{0 . 2 2} \\
-\mathbf{0 . 2 3 ^ { \star * }} \\
-0.01 \\
0.16 \\
-0.02 \\
\mathbf{0 . 2 0}^{\star} \\
-\mathbf{0 . 1 9 ^ { \star }} \\
\mathbf{0 . 2 4}^{\star}\end{array}$ & 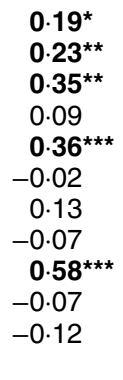 & 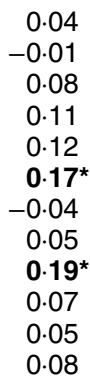 \\
\hline
\end{tabular}

F-R, food-related Restriction; F-MON, food-related Monitoring; F-MOD/ENC, food-related Modelling/Encourage balance and variety; F-INV/ENV, food-related Involvement/Environment; F-TN, food-related Teaching about nutrition; F-PE, food-related Pressure to eat; F-CC, food-related Child control; F-ER/FR, foodrelated Emotion regulation/Food as reward; A-MOD, activity-related Modelling; A-PC, activity-related Psychological control; A-PST, activity-related Promote screen time; A-T/AS; activity-related Teaching/Autonomy support; A-GO, activity-related Going outdoors. Bold values represent significant correlations.

${ }^{\star} P<0.05,{ }^{* *} P<0.01,{ }^{* * *} P<0.001$.

\section{Discussion}

The aim of the current study was to develop and take the first steps to validate a questionnaire for child-care staff to assess food-related and activity-related practices. Based on two validated parenting practices questionnaires, the $\mathrm{CFPQ}^{(35)}$ and the PPAPP ${ }^{(36)}$, and the previous work of Dev and colleagues ${ }^{(33,34)}$ to translate the CFPQ to the child-care setting, we developed and validated the Dutch version of the CFAPQ. The scales of the final CFAPQ showed sufficient internal consistency and CITC within acceptable ranges.

The CFAPQ consists of sixty-three items (forty foodrelated items and twenty-three activity-related), divided over twelve scales (seven food-related and five activity-related scales; see online supplementary material, Supplemental Table 3). The CFAPQ scales are to a large extent similar to those of the original $\mathrm{CFPQ}^{(35)}$ and PPAPP $^{(36)}$ scales. As regards the food-related scales, four CFAPQ scales were in line with the original CFPQ scales: Monitoring, Teaching about nutrition, Pressure to eat and Child control. The three other CFAPQ scales each combined two original CFPQ scales: Encourage balance and variety/Modelling, Environment/Involvement and Emotion regulation/Food as a reward. Regarding the activity-related items, two scales were the same as the original PPAPP scales: Psychological control and Promote screen time. The other items regarding encouragement were distributed over three scales: Modelling of physical activity, Teaching/Autonomy support of physical activity and Going outdoors.

The CFAPQ was developed based on existing parenting practices questionnaires for several reasons. First of all, the role of child-care staff at child care is very similar to parents' behaviour at home; with the increasing use of child care, child-care staff are becoming increasingly responsible for children's development during their early years ${ }^{(47)}$. As the parenting literature is much more advanced in this area, research in the child-care setting can, or, in our opinion, should, learn and benefit from this. There is, however, another advantage of developing instruments for the childcare setting in line with parenting instruments: it allows for comparison between both settings. In line with an ecological view on environmental influences on children's energy balance-related behaviours, attunement between the child-care setting and the home setting might be very important ${ }^{(48)}$. Studies regarding general child development have for instance shown that parents and child-care staff often have different child-rearing attitudes, values, attitudes and practices ${ }^{(49,50)}$, and that such inconsistencies have negative effects on children's well-being ${ }^{(50,51)}$. The same might be true for children's food-related and activity-related behaviours. Qualitative studies have repeatedly shown the impact that parents and child-care providers have beyond their own setting, influencing each other's practices as well as children's healthy energy balance-related behaviours in the other setting (e.g. references 52-56). This stresses the importance of parent-child-care partnerships. However, quantitative research regarding the importance of continuity between home and child care is lacking ${ }^{(48)}$. To be able to examine this, instruments are needed that can be used in both settings ${ }^{(48)}$. If different instruments are used to assess practices in the child-care setting than those used in the home setting, any difference between both settings might be caused by methodological flaws, instead of reflecting actual discontinuity. The development of the CFAPQ in line with parenting practices questionnaires allows for comparison of food-related and activity-related practices between the home and child-care settings. There were numerous correlations among the child-care practices scales of the CFAPQ, including cross-behavioural associations between food-related and activity-related practices.

There were various associations between the CFAPQ scales and background characteristics of the child-care staff. Compared with child-care staff who did have children themselves, child-care staff who did not have children more often used undesirable practices: they more 
often used food to regulate emotions or as a reward, and they more often used psychological control to regulate children's physical activity. A previous study by Dev and colleagues showed that child-care staff without children more often used pressure to eat ${ }^{(34)}$. These findings indicate that experience with children, including experience with staff's own children, might be an important predictor of positive food-related practices. In line with this, we found that experience within the child-care setting was associated with the use of food-related modelling and encouragement to eat healthily. However, Dev et al. ${ }^{(34)}$ did not find such an association between years of experience and any of the food-related practices.

Participants' educational level was not significantly related to any of the CFAPQ scales, which contrasts with the findings of Dev et al. in centre-based child care ${ }^{(34)}$ and with Brann in family day care ${ }^{(54)}$, both reporting more use of pressure to eat by lower educated staff. However, these previous studies compared college graduates with non-college graduates ${ }^{(34,57)}$, while the current study compared between three similar child-care staff educations, all at intermediate vocational education level. The differences between the levels might have been too small to detect any differences in relation to the scales. In addition, Dev et al. linked a number of other characteristics of child-care staff to the practices they use, which were not included in the current study. These included non-white ethnicity, authoritarian feeding style and whether the child-care staff member was trying to lose weight him-/herself, which were all linked to controlling practices $^{(34)}$. More research is needed to confirm these predictors, as well as to examine additional predictors. Research regarding food-related parenting practices has for instance shown that the child's temperament is associated with the practices used by the parents (e.g. reference 16). This might also be the case in the child-care setting. Furthermore, research is needed to examine predictors of activity-related practices, as, to our knowledge, no previous studies reported about this.

The current study had several limitations that need to be acknowledged. First, the sample size was relatively limited, with a sample size of 178 child-care staff members. Moreover, 1028 child-care centres were invited to participate in the study, indicating a maximum response rate of $17.3 \%$ (presuming each participating child-care worker was from a different child-care centre). This low response rate might reflect a selection bias, limiting the generalizability of our findings. Further research in larger samples is thus necessary. Specifically, caution is warranted when interpreting the subgroup analyses, as these analyses are potentially underpowered. Second, it is not known in how many child-care centres these 178 child-care staff members were employed. Child-care centres were approached randomly and asked to inform their employees about the study. We did not register at which child-care centre the participants were working. It was therefore not possible to correct for a potential multilevel structure of the data. If more than one child-care worker participated per centre, these child-care workers would be more alike than child-care workers from different centres, thus potentially explaining part of the associations found in the current study. Third, the associations between the practices and background characteristics were examined using bivariate analyses, thus not taking any potential confounding into account. Fourth, distributions of the answers to some of the items were very skewed and/or had limited variability. This might indicate social desirability bias. Strong points of the current study included building on validated parenting practices instruments ${ }^{(35,36)}$ and previous research in the child-care setting $^{(33,34)}$. In addition, the current study combined a qualitative in-depth pre-test with a quantitative pilot test. However, for further validation of the CFAPQ, studies examining the concurrent and predictive value of the questionnaire would be advisable. A good next step would be to examine associations between the CFAPQ scales and other staff characteristics such as physical activity and nutrition-related training and experience. Furthermore, future studies should look at possibilities to reduce the number of items, as the questionnaire is still quite lengthy at this point.

\section{Conclusion}

In conclusion, based on the results of the current study, the CFAPQ seems to be a valid questionnaire to assess child-care staff's energy balance-related practices, although more research is needed to confirm its validity. The CFAPQ can be used in studies to gain more insight into the use of energy balance-related practices in the child-care setting, predictors of the use of these practices and, perhaps most important, the effect that the practices have on children's behaviour. Such studies are urgently needed to gain insight into the role the child-care setting can play in obesity prevention and to inform future interventions in the child-care setting.

\section{Acknowledgements}

Acknowledgements: The authors thank all child-care staff for their participation in the validation studies. Financial support: This work was supported by a personal Veni grant (Innovational Research Incentives Scheme) from the Netherlands Organization for Scientific Research (NWO), Division for the Social Sciences (MaGW), the Netherlands (J.S.G., grant number 016.145.091); and the Netherlands Heart Foundation (E.F.C.S., grant number 2014T037). The funders had no role in the design, analysis or writing of this article. Conflict of interest: None. Authorship: J.S.G., E.F.C.S. and S.P.J.K. formulated the research questions and designed the study. L.C.H.R. and J.M.G. carried out the 
study. J.S.G. performed the descriptive and correlational analyses; E.F.C.S. performed the factor analyses. J.S.G. and E.F.C. wrote draft versions of the manuscript; L.C.H.R., J.M.G. and S.P.J.K. reviewed the draft versions. All authors approved the final version of the manuscript. Ethics of buman subject participation: Verbal informed consent was obtained from all subjects of the pre-test. Verbal consent was witnessed and recorded on tape.

\section{Supplementary material}

To view supplementary material for this article, please visit http://dx.doi.org/10.1017/S1368980015003444

\section{References}

1. Jones RA, Hinkley T, Okely AD et al. (2013) Tracking physical activity and sedentary behavior in childhood: a systematic review. Am J Prev Med 44, 651-658.

2. Craigie AM, Lake AA, Kelly SA et al. (2011) Tracking of obesity-related behaviours from childhood to adulthood: a systematic review. Maturitas 70, 266-284.

3. Golan M \& Crow S (2004) Parents are key players in the prevention and treatment of weight-related problems. Nutr Rev 62, 39-50.

4. Darling N \& Steinberg L (1993) Parenting style as a context: an integrative model. Psychol Bull 113, 487-496.

5. Gevers DW, Kremers SP, de Vries NK et al. (2014) Clarifying concepts of food parenting practices. A Delphi study with an application to snacking behavior. Appetite 79, 51-57.

6. Davison KK, Mâsse LC, Timperio A et al. (2013) Physical activity parenting measurement and research: challenges, explanations, and solutions. Child Obes 9, Suppl., S103-S109.

7. O'Connor TM, Hingle M, Chuang RJ et al. (2013) Conceptual understanding of screen media parenting: report of a working group. Child Obes 9, Suppl., S110-S118.

8. Hughes SO, Frankel LA, Beltran A et al. (2013) Food parenting measurement issues: working group consensus report. Child Obes $\mathbf{9}$, Suppl., S95-S102.

9. Larsen JK, Hermans RCJ, Sleddens EFC et al. (2015) How parental dietary behavior and food parenting practices affect children's dietary behavior. Interacting sources of influence? Appetite 89, 246-257.

10. Ventura AK \& Birch LL (2008) Does parenting affect children's eating and weight status? Int J Behav Nutr Phys Act 5, 15.

11. Sleddens EF, Kremers SP, Hughes SO et al. (2012) Physical activity parenting: a systematic review of questionnaires and their associations with child activity levels. Obes Rev 13, 1015-1033.

12. Vaughn AE, Tabak RG, Bryant MJ et al. (2013) Measuring parent food practices: a systematic review of existing measures and examination of instruments. Int J Behav Nutr Phys Act 10, 61.

13. Jago R, Edwards MJ, Urbanski CR et al. (2013) General and specific approaches to media parenting: a systematic review of current measure, associations with screenviewing, and measurement implications. Child Obes 9, Suppl., S51-S72.

14. Trost S, McDonald S \& Cohen A (2013) Measurement of general and specific approaches to physical activity parenting: a systematic review. Child Obes 9, Suppl., S40-S50.

15. Blackburn P (2006) Childcare services in the EU - what future? European Foundation for the Improvement of Living and Working Conditions. http://www.eurofound.europa. eu/observatories/emcc/articles/other/childcare-services-inthe-eu-what-future (accessed November 2015).

16. Gubbels JS, Kremers SP, Stafleu A et al. (2009) Diet-related restrictive parenting practices. Impact on dietary intake of 2 -year-old children and interactions with child characteristics. Appetite 52, 423-429.

17. Larson N, Ward DS, Neelon SB et al. (2011) What role can child-care settings play in obesity prevention? A review of the evidence and call for research efforts. J Am Diet Assoc 111, 1343-1362.

18. Johnston Molloy C, Kearney J, Hayes N et al. (2014) Healthy incentive scheme in the Irish full-day-care pre-school setting. Proc Nutr Soc 73, 147-158.

19. Gubbels JS, Kremers SP, van Kann DH et al. (2011) Interaction between physical environment, social environment, and child characteristics in determining physical activity at child care. Health Psychol 30, 84-90.

20. Gubbels JS, Kremers SP, Stafleu A et al. (2010) Child-care use and the association with body mass index and overweight in children from 7 months to 2 years of age. Int J Obes (Lond) 34, 1480-1486.

21. Geoffroy MC, Power C, Touchette E et al. (2013) Childcare and overweight or obesity over 10 years of follow-up. J Pediatr 162, 753-758.e1.

22. Vereecken C, Huybrechts I, Maes L et al. (2008) Food consumption among preschoolers. Does the school make a difference? Appetite 51, 723-726.

23. Hinkley T, Crawford D, Salmon J et al. (2008) Preschool children and physical activity: a review of correlates. Am J Prev Med 34, 435-441.

24. Gubbels JS, Gerards SMPL \& Kremers SPJ (2015) Use of food practices by childcare staff and the association with dietary intake of children at childcare. Nutrients 7, 2161-2175.

25. Gubbels JS, Kremers SP, Stafleu A et al. (2010) Child-care environment and dietary intake of 2- and 3-year-old children. J Hum Nutr Diet 23, 97-101.

26. Hendy HM \& Raudenbush B (2000) Effectiveness of teacher modeling to encourage food acceptance in preschool children. Appetite 34, 61-76.

27. Henderson KE, Grode GM, O'Connell ML et al. (2015) Environmental factors associated with physical activity in childcare centers. Int J Behav Nutr Phys Act 12, 43.

28. Bell AC, Finch M, Wolfenden L et al. (2015) Child physical activity levels and associations with modifiable characteristics in centre-based childcare. Aust N Z J Public Health 39, 232-236.

29. Ajja R, Beets MW, Chandler J et al. (2015) Physical activity and healthy eating environment audit tools in youth care settings: a systematic review. Prev Med 77, 80-98.

30. Ward D, Hales D, Haverly K et al. (2008) An instrument to assess the obesogenic environment of child care centers. Am J Health Behav 32, 380-386.

31. Ball SC, Benjamin SE, Hales DP et al. (2005) The Environment and Policy Assessment and Observation (EPAO) Child Care Nutrition and Physical Activity Instrument. Chapel Hill, NC: Center for Health Promotion and Disease Prevention, University of North Carolina.

32. Hughes SO, Patrick H, Power TG et al. (2007) The impact of child care providers' feeding on children's food consumption. J Dev Behav Pediatr 28, 100-107.

33. Dev DA \& McBride BA (2013) Academy of Nutrition and Dietetics Benchmarks for nutrition in child care 2011: are child-care providers across context meeting recommendations? J Acad Nutr Diet 113, 1346-1353.

34. Dev DA, McBride BA, Speirs KE et al. (2014) Predictors of head start and child-care providers' healthful and controlling feeding practices with children aged 2 to 5 years. J Acad Nutr Diet 114, 1396-1403.

35. Musher-Eizenman D \& Holub S (2007) Comprehensive Feeding Practices Questionnaire: validation of a new 
measure of parental feeding practices. J Pediatr Psychol 32, 960-972.

36. O'Connor TM, Cerin E, Hughes SO et al. (2014) Psychometrics of the preschooler physical activity parenting practices instrument among a Latino sample. Int J Behav Nutr Phys Act 11, 3.

37. Birch LL, Fisher JO, Grimm-Thomas K et al. (2001) Confirmatory factor analysis of the Child Feeding Questionnaire: a measure of parental attitudes, beliefs and practices about child feeding and obesity proneness. Appetite 36, 201-210.

38. O'Connor TM, Cerin E, Lee RE et al. (2014) Environmental and cultural correlates of physical activity parenting practices among Latino parents with preschool-aged children: Niños Activos. BMC Public Health 14, 707.

39. KOALA - STUDY website (2015) KOALA Birth Cohort Study, the Netherlands. http://www.koala-study.nl/researchers.html (accessed November 2015).

40. Willis GB (1999) Cognitive Interviewing. A 'How To' Guide. Research Triangle Park, NC: Reseach Triangle Institute.

41. Landelijk Register Kinderopvang (National Register Childcare) (2014) Homepage. http://www.landelijkregisterkinderopvang. $\mathrm{nl} / \mathrm{pp} /$ StartPagina.jsf (accessed March 2014).

42. Innovero Software Solutions BV (2014) Formdesk homepage. https://en.formdesk.com/ (accessed March 2014).

43. Portney LG \& Watkins MP (2000) Foundations of Clinical Research: Applications to Practice, 2nd ed. Upper Saddle River, NJ: Prentice Hall.

44. Bernstein IH \& Nunnally J (1994) Psychometric Theory. New York: McGraw-Hill.

45. Williams B, Onsman A \& Brown T (2010) Exploratory factor analysis: a five-step guide for novices. Australas J Paramed 8 (3), available at http://ro.ecu.edu.au/jephc/vol8/iss3/1/

46. Cattell RB (1966) The scree test for the number of factors. Multivariate Behav Res 1, 245-276.

47. Story M, Kaphingst KM \& French S (2006) The role of child care settings in obesity prevention. Future Child 16, 143-168.

48. Gubbels JS, Van Kann DH, de Vries NK et al. (2014) The next step in health behavior research: the need for ecological moderation analyses - an application to diet and physical activity at childcare. Int J Behav Nutr Phys Act 11, 52.

49. Kontos S (1987) The attitudinal context of family-daycare relationships. In Continuity and Discontinuity of Experience in Child Care, pp. 91-113 [DL Peters and S Kontos, editor]. Norwood, NJ: Ablex.

50. Tavecchio L, IJzendoorn Rv \& Stams GJ (1996) Onderzoek: kinderopvang en thuis twee gescheiden werelden. Kinderopvang 12, 24-27.

51. Van Ijzendoorn MH, Tavecchio LWC, Stams GJ et al. (1998) Attunement between parents and professional caregivers: a comparison of childrearing attitudes in different child-care settings. J Marriage Fam 60, 771-781.

52. Mena NZ, Gorman K, Dickin K et al. (2015) Contextual and cultural influences on parenting feeding practices and involvement in child-care centers among Hispanic parents. Child Obes 11, 347-354.

53. Tucker P, van Zandvoort MM, Burke SM et al. (2011) The influence of parents and the home environment on preschoolers' physical activity behaviours: a qualitative investigation of childcare providers' perspectives. BMC Public Health 11, 168.

54. Wilke S, Opdenakker C, Kremers SPJ et al. (2013) Factors influencing child care workers' promotion of physical activity in children aged 0-4 years: a qualitative study. Early Years 33, 226-238.

55. Baumgartner J \& McBride B (2009) Exploring parental philosophies regarding childcare: overlap orientations and the influence of childcare programmes on families. Early Child Dev Care 179, 931-947.

56. Lloyd-Williams F, Bristow K, Capewell S et al. (2011) Young children's food in Liverpool day-care settings: a qualitative study of pre-school nutrition policy and practice. Public Health Nutr 14, 1858-1866.

57. Brann LS (2010) Child-feeding practices and child overweight perceptions of family day care providers caring for preschool-aged children. J Pediatr Health Care 24, 312-317. 